\title{
СРАВНЕНИЕ ПЕРСОНАЛЬНЫХ АНТРОПОНИМИКОНОВ В УСЛОВИЯХ ИНТЕРНЕТ-КОММУНИКАЦИИ НА ПРИМЕРЕ ТРЁХ ЯЗЫКОВ (РУССКОГО/ АНГЛИЙСКОГО/ ИСПАНСКОГО)
}

\section{COMPARISON OF PERSONAL ANTHROPONYMICONS IN THE CONDITIONS OF INTERNET COMMUNICATION ON THE EXAMPLE OF THREE LANGUAGES (RUSSIAN / ENGLISH / SPANISH)}

\section{Novikova} A. Podgornova

Summary: The paper addresses the impact of the digital era on personal anthroponymicons and comparing e-mail addresses of Russian speaking, English speaking and Spanish speaking people. The aim is to see what effect the presence of a digital dimension has for development of anthroponymic formulas of Russian and Foreign language users. The findings reveal current trends in including specific anthroponymic information in e-mail addresses typical of a particular social group under study. Moreover, this article demonstrates the common moments and differences in the process of creating e-mail addresses of Russian and Foreign users.

Keywords: personal anthroponymicon, proper names, precedent name, questionnaire survey, trends, patterns, e-mail addresses.
B эпоху глобализации, всемирной информатизации, а в последнее время цифровизации [13] всех способов коммуникации по причинам мировой пандемии и «ухода человечества в онлайн» проблема самовыражения и утверждения себя в виртуальном мире стала первостепенной. По этой причине, мы считаем, что интерес для современного лингвиста-исследователя представляет механизм «рождения» номинативных единиц, олицетворяющих индивидуума на просторах глобальной сети.

В первую очередь считаем необходимым обозначить содержание понятия «антропонимико́н», под которым современными учеными понимается совокупность антропонимов, то есть собственных имён для именования человека в каком-либо языке [7, с. 12]. Антропонимикон какого-либо языка включает в себя все имеющиеся или бывшие в употреблении имена людей; в противоположность этому выделяется понятие име́нника - то есть имена, активно использовавшиеся в какой-либо исторический период, в какой-либо социальной группе, на какой-либо ограниченной территории. Именник, в отличие от антропонимикона, предполагает учёт реальной
Новикова Дарья Константиновна

к.филол.н., старший преподаватель, Санкт-Петербургский государственный университет novik0va.daria@yandex.ru

Подгорнова Анна Владимировна стариий преподаватель, ФГАОУ ВО «Дальневосточный федеральный университет» diamante-anna@mail.ru

Аннотация: Данная статья рассматривает влияние цифровой эры на формирование персональных антропонимиконов русско-, англо-, испаноговорящих пользователей электронных адресов. Цель статьи - увидеть каково влияние цифрового пространства на развитие антропонимических формул русских и зарубежных пользователей сети интернет. Данное исследование демонстрирует новейшие тенденции в формировании наименований электронных адресов, типичных для выбранной нами группы респондентов. Кроме того, данная статья показывает сходства и различия в процессе создания электронных адресов, как российских, так и зарубежных пользователей.

Ключевые слова: персональный антропонимикон, имена собственные, прецедентное имя, анкетирование, тенденции, закономерности, электронные адреса.

частотности имён [7, с. 20].

Как известно, онимы (имена собственные) вообще и антропонимы (имена личные) в частности неразрывно связаны с историей и культурой той страны, где они используются. Наличие или отсутствие в именнике определенного народа какого-либо набора антропонимов связано также и с экономическим развитием страны (например, послереволюционные имена Даздраперма - ДА ЗДРАвствует ПЕРвое МАя, Даздрасмыгда - ДА ЗДРАвствует СМЫчка Города и Деревни, Вилена - Владимир Ильич Ленин, Пятизатр - ПЯтИлетку ЗА ТРи года). Данное явление связано с приходом Советской власти в СССР, когда люди сами стали нарекать своих детей коммунистическими именами (раньше это делали церковнослужители). Поскольку антропонимы не имеют самостоятельного значения, а их главная роль - называть, а не значить, следовательно, они являются весьма существенными. Происходит это, прежде всего, потому что для окружающих они бесспорно указывают на чёткую традицию именования, принятую в данном обществе [10, с. 176].

Рассмотрев передовой опыт филологов, занимаю- 
щихся изучением антропонимов, мы пришли к выводу, что в сфере науки антропонимики отсутствует один важный элемент, а именно антропонимикон, относящийся непосредственно к самонаименованию человека, его самоопределению в социокультурной среде. Мы считаем, что данный термин можно определить, как персональный антропонимикон, то есть личное восприятие индивидом своего имени и его воспроизведение (различные вариации) в социокультурном контексте (а именно, в повседневной жизни).

В качестве примера рассмотрим абстрактного человека с именем Иван Иванович Иванов. Скорее всего, для серьёзной работы этот индивид пользуется именем и отчеством, для коллег по работе он может быть просто Иванычем, для друзей - Ванькой, для жены - Ванюшей, для деловой переписки использовать фамилию и инициалы, а для личного почтового ящика или ника в социальных сетях, например, - самонаименование agent007 (данное наименование может возникнуть, как вариант, благодаря личным кино-предпочтениям человека). Последнее перекликается с термином персональный антропонимикон (далее антропонимикон), под которым мы понимаем самоолицетворение себя с каким-либо именем, будь это производное от собственной фамилии с именем, или абсолютно отвлеченное понятие, слово, прозвище или же прецедентное имя, отряжающее социокультурный пласт эпохи [5, С. 100-155]. В более широком понимании прецедентные феномены уже связаны с явлением интертекстуальности, что свидетельствует о связи одного антропонимикона с другими, похожими на него и легко узнаваемыми всеми участниками, объединенными общими интересами или принадлежащие к одной языковой среде.

В данной статье для анализа антропонимиконов были использованы методы анкетирования\онлайнанкетирования (виртуальный опрос респондентов с помощью сервиса google.docs) и личный контакт (как уточняющий способ связи с исследуемой аудиторией).

Избранная нами целевая аудитория представлена респондентами в возрасте от 18 до 60 лет, проживающими на территории РФ, США, Великобритании, Испании и испаноязычных стран, которая имеет различное социальное положение, уровень образования и специальность. Поэтому анализ данных был нами разделен на три блока, отдельно для каждой языковой среды (русско-, англо- и испаноязычной), чтобы проследить схожие и различные черты «рождения» антропонимиконов.

Для онлайн-сбора материала были использованы многочисленные источники, среди которых такие сайты, как www.tiwy.com, www.busuu.com/ru, www.sharedtalk. com, и многие другие, а также популярные социальные сети Instagram, Facebook. Кроме того, материалом для научного исследования стали результаты проведенного письменного опроса студентов и магистрантов неязыковых специальностей, а также преподавателей в возрасте от 22 до 60 лет.

Считаем важным подробнее остановится на вопросах анкеты, предоставленной для сбора эмпирического материала. Всего нами было их составлено 16. В свою очередь, первые 8 вопросов являются социо-гендерными (пол, возраст, род занятий, образование, страна проживания, родной язык и собственно антропонимикона e-mail адреса). 9 вопрос непосредственно является нашим языковым материалом - он отражает мотивы, побудившие выбрать именно этот электронный адрес. 10 и 11 вопросы позволили установить, как анкетируемые подходили к обозначению своего виртуальной почты: «серьёзно и вдумчиво, рассчитывая на продолжительный срок его использования» или «легко и быстро, считая, что при желании данный адрес можно изменить». 12 вопрос выяснил насколько серьёзным был подход к выбору электронного адреса, является ли он на сегодняшний день неотъемлемой частью своего владельца, который планирует его использование в дальнейшем или это временный ник, с которым анкетируемый не связывает своего будущего. 13 и 14 вопросы позволили выявить наличие никнейма (-ов) в социальных сетях, 15 уточнил детали его появления и финальный 16 касался наличия домашнего прозвища респондента, а также истории его появления, что позволило нам установить концептуальную связь между всеми антропонимиконами (домашним именем, наименованием адреса электронной почты и никнеймом). Данные анкеты находятся в открытом доступе в сети Интернет $[14,15,16]$ :

\section{Блок 1 (русскоязычные респонденты)}

Нами было опрошено 500 респондентов. Анализ наименований электронных адресов русскоязычных носителей позволил сделать следующую классификацию:

І. Творческие названия электронных адресов, не включающие в свой состав персональное имя/ фамилию;

II. Творческие названия электронных адресов, включающие в состав персональное имя/ фамилию;

III. Официальные наименования, включающие в свой состав полностью ФИО, только инициалы или различные комбинации;

IV. Алогичные названия электронных адресов, то есть не поддающиеся логике и осмыслению, включающие в свой состав непонятные и/ или необъяснимые буквенные или цифровые сочетания.

В данную статью мы включили лишь некоторые наиболее яркие, на наш взгляд, примеры из каждой группы (подгруппы). 
Итак, в первую категорию мы ввели следующие 4 подкатегории:

1.1. Названия на иностранном языке: einenacht (с немецкого «одна ночь», название придумано вследствие любви к немецкому + мировоззрения), culinary-fairy (данное название связано с хобби респондентки, придумано ее дочерью), sporty-g (название может быть расшифровано как sporty girl, отражающее активную жизненную позицию респондентки), la_perla_negra (с испанского «черная жемчужина», появилось вследствие увлечения респондентки аргентинскими сериалам), theremix (название отсылает к типу музыки ремикс на оригинальные песни), panther (любимое животное), theclearskill (в подростковом возрасте респондентка думала, что хороша в любом виде творчества), kamigamiteiru (от японского «бог смотрит»), chimitsu2147chimitsu 干(chi) - тысяча; 密 (mitsu) - тайна; это сочетание показалось автору интересным, uncleed111 (в переводе с английского «дядя Эд», автора зовут Эдуард + случайные цифры, предложенные системой;

1.2. Псевдонимы, ники в социальных сетях, онлайниграх: emilidione (сокращение от личного псевдонима в артистической среде Эмилия Достоевская), silvia.lanuit (псевдоним в актерской среде), lilyaosinhabitant (ностальгические вспоминания из детства), megakochka (из-за увлечения силовыми тренировками от «мега качок»), maestro1900 (любимый персонаж сериала + год рождения этого самого персонажа), vaуре94 (искажённое слово «вампир», из-за увлечения фильмами такого рода + первое, которое пришло в голову число), solidsound66 (творческий псевдоним, т.к. автор данного электронного адреса превосходно рисует и представляет свои картины в онлайнконкурсах для художников + спонтанное число), vakabakayo - детское прозвище + baka «дурак» и уо восклицание на японском;

1.3. Личные предпочтения, включающие прецедентные имена, такие как герои мультфильмов, кино, книг и имена домашних животных и прочее: ilovemukuro61 (имя любимого аниме-персонажа + любимое число), Lavlet (фамилия героя аниме), 37115 kitniss (случайные цифры + слово после просмотра «Голодных игр»), jess (от имени любимой кошки), amfibia_97 (по названию книги), afelia2 (автор хотела взять себе псевдоним из Гамлета, но этот ник был уже занят, поэтому пришлось поменять букву «о» на «а», и добавить «2»), flora (по имени героини из мультфильма Винкс), astraltair (в переводе «звезда Альтаира», появилось после просмотра кинофильма), unwritenlaw (специально употреблённое с ошибкой наименование, от названия музыкальной группы «unwritten law», т.е. «неписанные правила», rabid132 (любимая компьютерная игра «raving rabids», korriandr любимая специя в кулинарии), nakksage - имя персонажа компьютерной игры;

1.4. Легко запоминаемые названия: dv.41.kamchatka (инициалы, код региона, малая родина), qwertyghjkl (удобная для запоминания последовательность на клавиатуре), zastegniglaza404 (в тот момент четко передавало состояние автора).

Вторая категория (включающая творческие названия электронных адресов с персональным именем/ фамилией), подразделена на 2 подкатегории:

2.1. Имя/ фамилия + дополнительный компонент: diamante-anna («бриллиант» в переводе с испанского + личное имя), vala-c (сокращение от фамилии + первая буква имени), elena-torn (имя + прецедентная фамилия персонажа из фильма «Звёздная пыль»), ushakov_horosh (по созвучию слов), snowy polina (имя + «снежное» прилагательное), semenliderori (автор зарегистрировался в компании Oriflame и хотел добиться карьерных высот: лидер + своё имя semen), annamajito1997 (имя + название напитка + год рождения), kirill14032000 (имя + дата рождения), maksim.man.nikiforov (имя + «мужчина» + фамилия), daryasun88 (имя + «солнце» с англ. + год рождения), margarita_teacher (имя + профессия), nastya-italy (респондентке нравились в детстве итальянские машинки, anastasiya-vlk (имя + сокращенное название родного города Владивостока;

2.2. Видоизмененное имя или гибрид имени и дополнительного элемента: godsson (перевод имени Богдан по мнению друга-американца), svetlan (производное от имени), marialex (из начала имени и отчества), ylia_american_football (имя + хобби), milena1012 (трансформированное имя Елена), superni-c (соединение слов super + сокращение от имени Николай), soniasss (имя + тройное сочетание sss), pem66 (аббревиатура от фамилии + год рождения), gallomania2012 (производное от имени Галина + год возникновения у респондентки электронной почты), uliya_378g (имя + абстрактное число и буква на конце), pigeonson (слияние имени Соня и прозвища «голубь»), di.dandelion.di (сокращенное от имени Диана + ник «одуванчик» + первые две буквы имени), ninapola63 (сокращенное имя + имя бабушки респондентки), pups kate_ups (отражение внутреннего ощущения респондент в определённый период жизни), nastella (гибрид между именем Анастасия и шоколадной пасты Nutella), tori rorik (сокращенная форма имени Виктория + забытое школьное прозвище), ilyagraf (юноша присоединил к имени титул в целях повышения авторитета в школе).

Третья категория (включающая официальные наи- 
менования, имеющие в своем составе ФИО, инициалы) подразделена на 2 подгруппы:

3.1. Наименования, не включающие числа в свой состав: el.shastina, ilincevi, nOvikOva.daria, pak_sm, lena_petrochenko, arina-shmakova, sidelnikova, sviyazovalentina (совмещение фамилии и имени, пропустив один общий слог), kate.ally.ab (имя + прозвище + первые буквы фамилии), alinaozhereleva (имя + фамилия), nesterova.ag (имя + инициалы), oh.gonggeon (имя и фамилия, автор данного автора иностранец);

3.2. Наименования, включающие цифры (значимые и спонтанные): irina.ushakova.16, victorZav1960 (имя + сокращение фамилии + год рождения), bondarchyk873 (фамилия + понравившаяся комбинация цифр), victoria2012timchenko (имя + фамилия + год создания почты), liza199216 (имя + последние цифры номера телефона), konstantinova888 (фамилия + случайные цифры), elen-p96 (видоизменённое имя Елена + первая буква фамилии и год рождения).

Четвертая категории состоит из алогичных названий электронных адресов, не поддающиеся логике и осмыслению, включающие в свой состав непонятные и/ или необъяснимые буквенные или цифровые сочетания: useqwe15, ntlptrv31, fasdy90, TheVaisMe, Qiwi.zone, dmabro13, dg_bsd, selcouthwld, mekshun_12, nozi1488, ns5157799, v.obv, tuubc.

Bce проанализированные нами антропонимиконы (500) в русскоязычном сегменте в процентном соотношении можно увидеть на Диаграмме1.

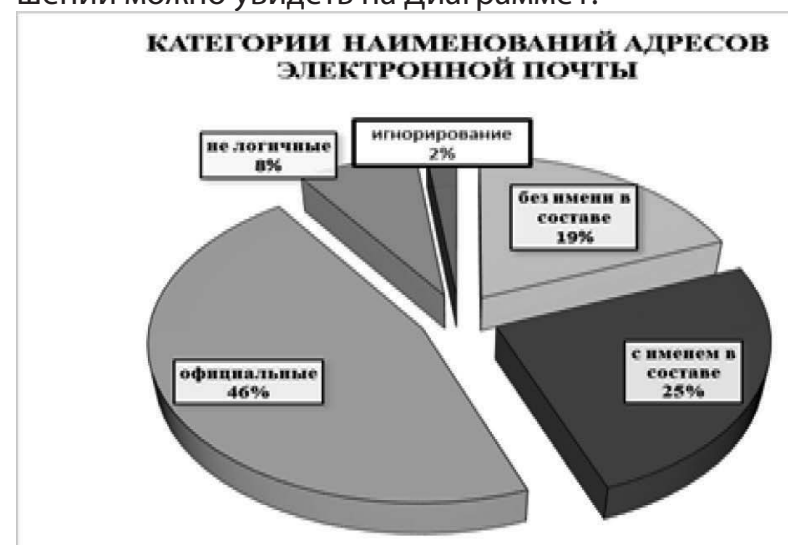

Диаграмма 1. Категории антропонимиконов адресов электронной почты русскоязычных респондентов

Стоит уделить внимание категории «игнорирование», а именно: откровенное пренебрежение анкетой, т.е. фактически респондент заполнил опросник, но написал во всех графах одно (порой не всегда приличное) слово, или оставил пропуски во всех графах анкеты. Данная нечастая тенденция, вероятнее всего, связана с нежеланием сообщать какую-либо информацию о себе, может быть, с психологической неустойчивостью, или личной неприязнью к подобного рода опросам.

\section{Блок 2 (англоязычные респонденты)}

Нами было опрошено 250 респондентов, среди которых англичане, американцы, канадцы, австралийцы, рожденные от смешанных рас (американец + грек, канадец + француз), а также иммигранты.

Как и в Блоке 1 мы включили лишь некоторые наиболее яркие, на наш взгляд, примеры в каждую группу:

І. Официальные наименования, включающие в свой состав ФИО, инициалы: kovalchik.s (фамилия + первая буква имени), JamieStone123 (имя + фамилия + случайное число), pasflorez.93 (полное имя + год рождения), danzan.g (имя + первая буква фамилии), FrancinePhillips0104 (имя + фамилия + дата рождения);

II. Творческие названия электронных адресов, включающие имя/ фамилию и/ или прецедентное имя: helenrain 12 (имя + «дождь» + дата создания анкеты), SamanthaJohns (имя + фамилия героини из сериала «Секс в большом городе» из-за совпадения имени и жизненных приоритетов), JackJet777 (имя + школьное прозвище + любимое число), JesStar (имя Джессика + «звезда» соединенное в одно слово), Elenamazingirl (имя + «замечательная девочка», соединенное в одно слово), natachamaksim2000 (имя + сокращение от «максимум» + год рождения), katyper2000 (сокращение от Кэти Пэрри + год рождения), littleponyAmber (прозвище «маленькая пони» + имя), Carla_sensation (имя + «сенсация»), Ruby_Gladys_love (первое имя + второе имя + «любовь»), SorrymoryLoli (замысловатая фраза + сокращение от имени Лолита), utopiangirlMeaghan (прозвище + имя);

III. Антропонимиконы не включающие в свой состав имя/ фамилию, отражающие личные предпочтения респондентов: JackDaniels090999 (название алкогольного напитка + дата рождения), Muskat787 (имя кошки + случайные цифры), Yugaypl (без объяснения причин), ya.loloka2013 (прозвище + год создания электронного адреса), crazyfrog (название песни), Djenka.fa (ник из компьютерной игры), tellmewhy (фраза из песни), irgasheval10 (слово + идеальное число), da_rek (спонтанное название).

Bсе проанализированных нами антропонимиконы (250) в англоязычном сегменте в процентном соотношении можно увидеть на Диаграмме 2.

Особое внимание стоит уделить анализу 2 и 3 категорий. Нам кажется, что такое разнообразие антропонимиконов вызвана тем, что наличие в имени только цифрового кода делает личность ненастоящей, «робо- 
тизированной», поэтому многие стремятся выделиться среди огромного числа однообразных наименований, показав свою индивидуальность. Например, если вы являетесь человеком по фамилии Адамс с именем Ричард, и вероятнее всего имеете множество полных однофамильцев, то есть большая вероятность, что система создания электронных имён в интернете выдаст вам что-то похожее на richard_adams331510 или RichardAdams331510, где цифра будет всего вашим порядковым номером среди людей с такими же именем и фамилией.

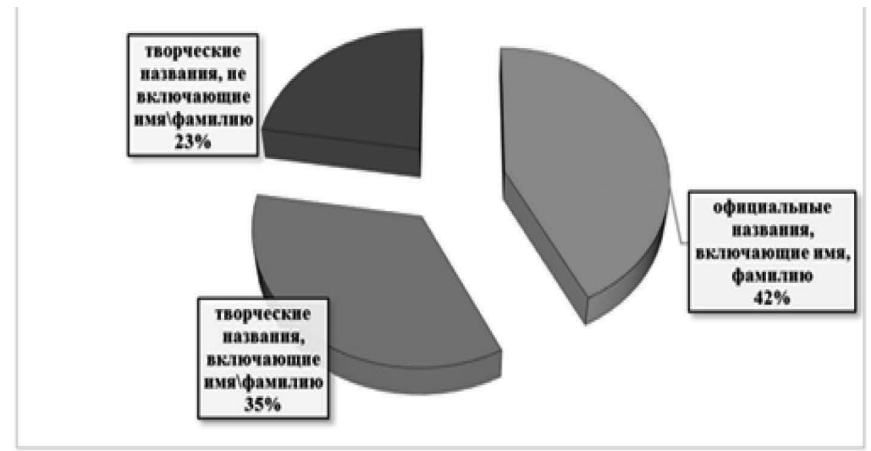

Диаграмма 2. Категории антропонимиконов адресов электронной почты англоязычных респондентов

\section{Блок 3 (испаноязычные респонденты)}

Нами было опрошено 250 человек, среди которых испанцы, мексиканцы, латиноамериканцы, живущие в Испании постоянно, или приехавшие в Испанию по работе. Анализ наименований электронных адресов испаноязычных респондентов позволил нам сделать следующую классификацию:

I. Официальные наименования, включающие в свой состав ФИО, инициалы: ahmed1 ramirez (имя + случайная цифра + фамилия), pasflorez.93 (имя + фамилия + год рождения), patry.uribe77 (сокращенный вариант имени + фамилия + год рождения), juancorrea0277 (имя + фамилия + дата и год рождения), LiliGomez (имя + фамилия), Lauralopez0909 (имя + фамилия + дата рождения);

II. Творческие названия электронных адресов, включающие имя/ фамилию и/ или прецедентное имя: JoseSanchesAlegría (имя + фамилия + прозвище «радость»), Marisasweeeetgirl (имя + «сладкая девочка», соединенные в одно слово), LindaLoo (имя + прозвище), RosarioClementinaGata (имя + второе имя + прозвище), ClaraDinero333 (имя + прозвище «деньги» + любимое число), Emilia_amor (имя + «любовь»), kenzolivia (любимая марка духов + имя), Liliana0809 (имя + дата рождения), SuperMario222 (название компьютерной игры + случайное число);

III. Творческие названия электронных адресов, не включающие в свой состав имя/ фамилию, отражающие личные предпочтения респондентов: Siempretristegatito (прозвище «всегда грустный котяра» без пробелов и отступов), querrida060607 («дорогая» + случайные числа), Amor1213 («любовь» + случайное число), chico_yo («мальчик» + «я»), nunca_quiero_amar («никогда не хочу любить»), cooocooo («куку»), latina1970 («латина» + год рождения), perfecta22 («идеальная» + возраст), amigo_444 («друг» + случайное число).

Bce проанализированных нами антропонимиконы (250) в испаноязычном сегменте в процентном соотношении можно увидеть на Диаграмме 3.
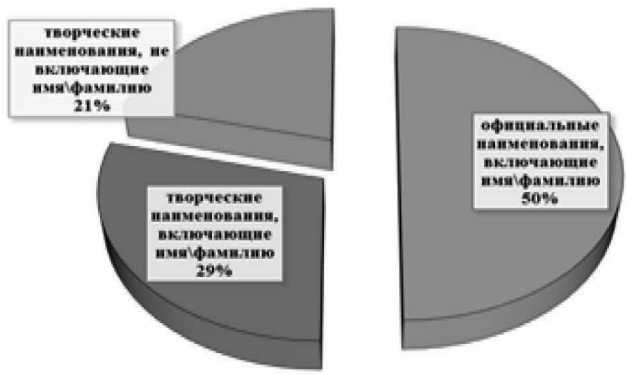

Диаграмма 3. Категории антропонимиконов адресов электронной почты испаноязычных респондентов

После проведенного анализа электронных адресов и других наименований (никнеймов/ логинов/ прозвищ) на примере трёх лингвокультур нами было выявлено, что сбор сведений такого рода - очень сложный процесс в современной политической обстановке, так как некоторые данные воспринимаются иноязычными респондентами как излишне личные, поэтому при составлении анкет-опросников необходимо очень тщательно продумывать каждый вопрос. Вследствие чего русскоязычный вариант анкеты и его иноязычные аналоги могут значительно отличаться. Интересно отметить, что возрастная категория от 18 до 35 лет является самой искренней (во всех лингвокультурах), откровенно предоставляет личные данные, истории появления своих антропонимиконов и с большим желанием идёт на контакт. Особого внимания заслуживает тот факт, что род занятий и уровень образования никак не влияет на процесс наименования электронных адресов опрошенных респондентов, за исключением безработных (так как наличие корпоративной почты не является для них важной необходимость, но наличие данного вида почты у работающего населения прочно входит в повседневную жизнь). Примечательно, что среди русскоязычных респондентов очень отчетливо прослеживается тенденция представления западного аналога/ варианта своего имени (за исключением полностью русских/ славянских имён). Мы также увидели закономерность, которая демонстрирует, что количество крайне креативных наименований адресов электронной почты значительно снижается, в отличие от никнеймов в онлайн-среде, где данные наименования находятся на самом пике. 


\section{ЛИТЕРАТУРА}

1. Авчиева Д.Т. Структурно-семантические особенности никнеймов современного русского языка полиэтнического города: автореф.дис.канд.филол.наук. Махачкала, 2016. -28 c.

2. Аникина Т.В. Сопоставительное исследование виртуального антропонимикона англоязычных, русскоязычных и франкоязычных чатов: автореф. дисс....к.филол.н. Екатеринбург, 2011. - 23 с.

3. Ермолович Д.И. Имена собственные на стыке языков и культур / Д.И. Ермолович. М.: Р.Валент, 2006. - 200 с.

4. Кубрякова Е.С. Теория номинации и словообразование. Монография. Изд. 3-е. - М.: Изд-во ЛИБРОКОМ, 2009.

5. Новикова Д.К. Функционально-прагматические особенности демонологической лексики (на материале текстов фантастической прозы): дис. ... канд. филол. наук: 10.02.19 / Новикова Дарья Константиновна. - Ставрополь, 2017. - 228 с.

6. Рылов Ю.А. Имена собственные в европейских языках. Романская и русская антропонимика / Ю.А. Рылов. - М.: АСТ: Восток - Запад, 2006. - 311 с.

7. Словарь лингвистических терминов Академик [Электронный ресурс]. - URL: https://dic.academic.ru/dic.nsf/lingvistic/

8. Сулейменова Д. Использование электронной почты и виртуального имени в интернет-коммуникации, Вестник КазНУ, Алматы, 2018.

9. Суперанская А.В. Общая теория имени собственного / А.В. Суперанская. М.: Книжный дом «ЛИБРОКОМ», 2009. - 368 с.

10. Тычинский А.А. Анализ современного состояния антропонимикона в Великобритании и США, Филологические науки. Вопросы теории и практики, Тамбов: Грамота, 2018, № 5, - С. 176-180.

11. Якунина М.Л. Особенность интернет-дискурса: никнейм // Филологические науки. Вопросы теории и практики. Тамбов: Грамота, 2013. № 3 (21). Ч. II. - 221 с.

12. Ресурс по созданию виртуальных опросов [Электронный ресурс]. - URL: https://www.testograf.ru/ru/provedenie/poleznie-soveti/skolko-respondentovnuzhno-dly.html

13. Разработчик цифровых моделей компаний [Электронный ресурс]. - URL: https://center2m.ru/digitalization-technologies

14. Виртуальная анкета для русскоговорящих респондентов опроса [Электронный ресурс]. - URL: https://docs.google.com/forms/d/e/1FAlpQLScPA8SOcDOffKm jOGzRNFLCGyY4wFqQ3v0QpWPjSulNb5LJnw/viewform?vc=0\&c=0\&w=1

15. Виртуальная анкета для англоговорящих респондентов опроса [Электронный ресурс]. - URL: https://docs.google.com/forms/d/e/1FAlpQLSdACL-SJOGPZNG5 gczhNCrsIWMnkim0jN7k8C0394E_Rw-xkw/viewform?vc=0\&c=0\&w=1

16. Виртуальная анкета для испаноговорящих респондентов опроса [Электронный ресурс]. - URL: https://docs.google.com/forms/d/e/1FAlpQLSfsyNet10X7_ w09EIBk2hrkWwGZGp55nLORo0T1JoGXTQijPw/viewform?vc=0\&c=0\&w=1

( ) Новикова Дарья Константиновна (n0vik0va.daria@yandex.ru), Подгорнова Анна Владимировна (diamante-anna@mail.ru). Журнал «Современная наука: актуальные проблемы теории и практики»

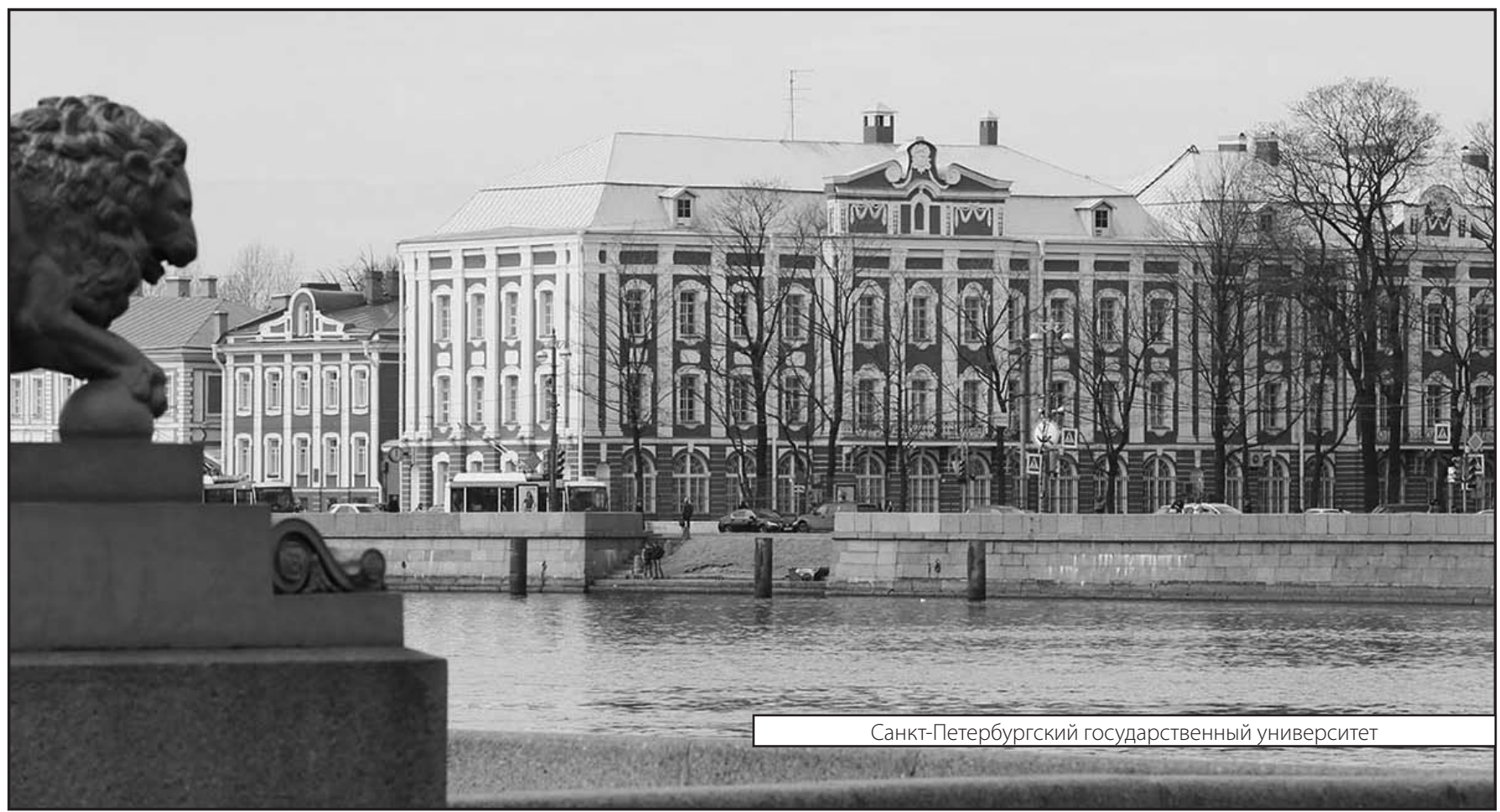

